\title{
ANALISA VARIASI DIAMETER LUBANG NOZZLE TERHADAP KARAKTERISTIK SPRAY MINYAK KELAPA DENGAN MINYAK KAPUK (B50) PADA PEMBAKARAN DIFUSI
}

\author{
Wigo Ardi W \\ Teknik Mesin, Fakultas Teknik \\ Universitas Maarif Hasyim Latif, Sidoarjo, Indonesia \\ e-mail : wigoardi13@gmail.com
}

\begin{abstract}
ABSTRAK
Minyak bumi sebagai sumber utama bahan bakar mengakibatkan cadangan minyak bumi menurun. Perlu adanya upaya untuk mengganti minyak bumi dengan bahan bakar lain didapat dari tanaman atau hewan. Tanaman penghasil minyak nabati salah adalah minyak kelapa dan kapuk. Untuk mendapatkan pembakaran sempurna, perlu dilakukan penelitian menggunakan metode pembakaran spray/difusi dengan menggunakan variasi diiameter nozzle $0,2 \mathrm{~mm}, 0,4 \mathrm{~mm}$ dan 0,6 $\mathrm{mm}$ dengan bentuk spray solid cone dan tekanan yang konstan 50 bar. Bahan bakar yang digunakan campuran antara minyak kelapa dengan minyak kapuk (B50). Diameter droplet yang dihasilkan semalin besar berbanding lurus dengan diameter nozzel yang semakin besar. Bertambahnya panjang nyala api dipengaruhi oleh meningkatnya diameter nozzle. Semakin meningkatnya sudut spray seiring dengan semakin besarnya diameter nozzle. Dengan variasi penyalaan awal, flashback hanya terjadi pada jarak penyalaan awal $500 \mathrm{~mm}$. Terjadi perbedaan turbulensi pada variasi nozzle, semakin besar diameter nozzle maka semakin besar turbulensi nyala api yang terjadi.
\end{abstract}

Kata kunci: diameter droplet, flashback, nozzle, minyak nabati (blending 50), pembakaran spray

\section{PENDAHULUAN}

Minyak bumi sebagai sumber utama bahan bakar mengakibatkan cadangan minyak bumi mengalami penurunan culup drastis. Maka perlu upaya untuk mengganti dengan minyak nabati yang dapat diperbaharui untuk mengganti atau paling tidak menghemat minyak bumi(Denitasari, 2011). Bahan bakar baru yang dapat adalah minyak nabati. Tanaman yang tumbuh di indonesia dan dapat menghasilkan minyak nabati salahsatunya kelapa dan kapuk. Namun B50 minyak nabati yang dihasilkan dari buah kelapa dan biji kapuk memiliki viskositas, densitas, tegangan permukaan dan titik nyala lebih tinggi jika dibandingkan minyak bumi. Sifat - sifat tersebut dapat mengakibatkan proses deformasi minyak nabati akan menjadi lebih sulit Pada proses atomisasi bahan bakar salah satunya dipengaruhi oleh tekanan, bentuk nozzle dan diameter nozzle. Karakteristik spray seperti sudut spray, kecepatan spray dan droplet yang didistribusikan, dapat ditentukan menggunakan diameter nozzle dan tekanan pada proses atomisasi. Droplet yang didistribusikan dikatakan sempurna jika memiliki ukuran kecil dan halus. Karakteristik droplet ini memiliki efek signifikan terhadap pembakaran spray, diameter droplet berkaitan dengan energi dari pembakaran tersebut, baik berupa cahaya, temperatur, radiasi dan emisi. Semakin kecil droplet hasil proses atomisasi maka energi yang semakin besar dihasilkan pada saat pembakaran berlangsung. Hal ini disebabkan butiran droplet dapat terbakar secara sempurna(Udin, Yuliati, \& Novareza, 2017). Penelitian tentang karakteristik spray minyak jarak pernah dilakukan oleh (Sudarmanta, 2017) dimana density yang tinggi menghasilkan penetrasi dan droplet fase cair bertambah, sedangkan distribusi fase gas lebih sempit. Begitu juga kecepatan terbentuknya semprotan cenderung melambat seiring dengan bertambahnya viskositas (Pinto, 2015). Tekanan berpengaruh pada karakteristik spray yang terjadi. Peneitian tentang variasi tekanan pernah dilakukan (Juniarta, Wirawan, \& Ghurri, 2017) Terjadi peningkatan sudut spray pada saat tekanan dinaikkan. Sedangkan distribusi besar droplet yang terbentuk pada masing - masing variasi tekanan mengalami peningkatan baik dari kecepatan spray, sudut spray (Wibawa, Bagus, Kusuma, \& Nyoman, 2015) dan ukuran droplet semakin kecil (Wirawan, Wardana, Soenoko, \&Wahyudi, 2014). Untuk mengetahui diameter droplet B50 minyak kelapa dan biji kapuk yang dapat terbakar sempurna maka pada penelitian ini dilakukan pengujian dengan variasian diameter lubang nozzle.

\section{METODE PENELITIAN}

Pada penelitian ini data yang dihasilkan berupa video. Pengambilan data dan visualisasi sudut spray, Panjang nyala api, flashback, dan turbulensi nyala api pada saat penelitian, menggunakan variasi diameter 
lubang nozzle 0,2 $\mathrm{mm}$; 0,4 mm; 0,6 mm dengan model spray solid cone dan dengan tekanan konstan yaitu 50 bar. Untuk mendapatkan data sudut spray, Panjang nyala api, flashback, dan turbulensi nyala api dengan menggunakan kamera Canon 1100 D dan. Untuk menentukan sudut spray, Panjang nyala api, flashback, dan turbulensi nyala api maka data pengujian kemudian diolah dengan menggunakan aplikasi Free Video to JPG Converter, kemudian skala dirubah mengikuti skala aslinya menggunakan aplikasi Image J, dan untuk mengetahui sudut spray, Panjang nyala api, flashback, dan nyala api turbulen ditentuan dengan Corel Draw.

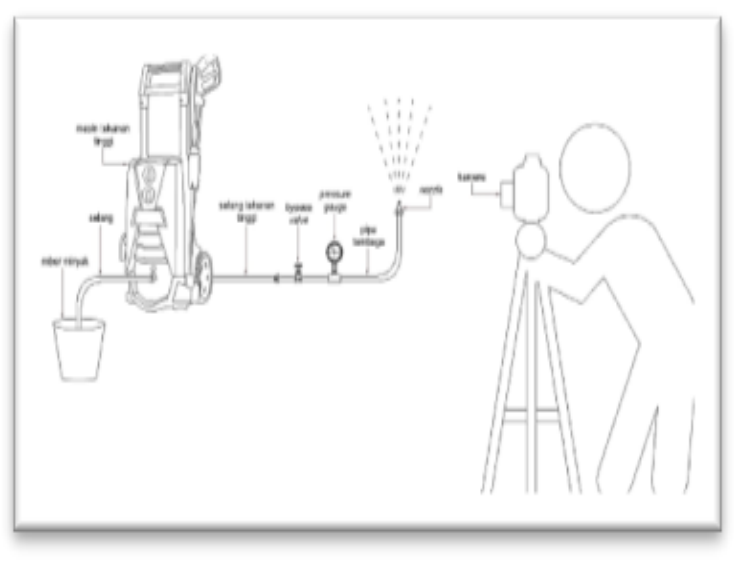

Gambar 1 Skema alat uji

\section{HASIL DAN PEMBAHASAN}

\section{Data penelitian}

Berikut adalah Analisa dari hasil pengujiian spray dengan menggunakan campuran bahan bakar minyak kelapa dengan minyak kapuk (B50). Data yang di ambil pada pengujian spray tersebut meliputi sudut spray, panjang nyala api, dimensi droplet dan flashback nyala api pada bebberapa posisi dengan lubang nozzle yang difariasian.

\section{Data alat uji}

Untuk mengetahui data secara teoritis maka diperlukan data data sebagai berikut:

Diameter lubang nozzle : 0,2 $\mathrm{mm} ; 0,4 \mathrm{~mm} ; 0,6 \mathrm{~mm}$

Tekanan pada nozzle : 50 bar

\section{Data bahan bakar}

Data bahan bakar diperlukan untuk mengetahui sudut, diameter droplet, kecepatan injeksi, debit dan waktu yang dibutuhkan droplet mencapai jangkauan paling jauh. Berikut merupakan data bahan bakar minyak blending (B50) kelapa dan kapuk:
1. Densitas
: $955 \mathrm{~kg} / \mathrm{m}^{3}$
2. Viskositas kinematic $: 50,55 \mathrm{~mm}^{2} / \mathrm{s}$
3. Tegangan permukaan : $32 \mathrm{Ns} / \mathrm{m}$

\section{Data perhitungan penelitian} Kecepatan injeksi bahan bakar kecepatan semprotan bahan bakar dapat diperkirakan secara teoritis menggunakan rumus persamaan sebagai berikut(Liguang, 2007).

$\mathrm{v}_{\mathrm{i}}=\mathrm{C}_{\mathrm{d}} \sqrt{\frac{2 \Delta \mathrm{p}_{\mathrm{i}}}{\rho_{l}}}=65,49 \mathrm{~m} / \mathrm{s}$

Karena kecepatan semprotan awal bahan bakar sudah diketahui secara teoritis maka untuk mengetahui kecepatan semprotan bahan bakar rata-rata dapat ditentukan menggunakan rumus berikut

$\mathrm{v}_{\text {mean }}=\frac{\dot{m}_{i}}{\rho_{l} \mathrm{~A}_{\text {hole }}}=65,46 \mathrm{~m} / \mathrm{s}$

Diketahui nilai Vmean yang diperoleh dari perhitungan secara teoritis didapat nilai sebesar $65,46 \mathrm{~m} / \mathrm{s}$.

\section{Diameter droplet}

Karena keterbatasan alat untuk mengukur droplet secara actual, maka untuk mengetahui besar butiran droplet hasil dari atomisasi bahan bakar dapat diperkirakan menggunakan persamaan Sauter Mean Diameter atau $\mathrm{D}_{32}$ berikut(Subbarao, n.d.) :

$\mathrm{D}_{32}=4.12 \mathrm{~d}_{\mathrm{n}} R e^{0,12} W e^{-0,75}\left\{\frac{\mu_{f}}{\mu_{a}}\right\}^{0,54}\left\{\frac{\rho_{f}}{\rho_{a}}\right\}^{0,18}$

$D_{32}=0,018 \mathrm{~mm}$

Pada grafik bawah ini menjelaskan terjadi peningkatan diameter droplet pada setiap nozzle variasi nozzle.

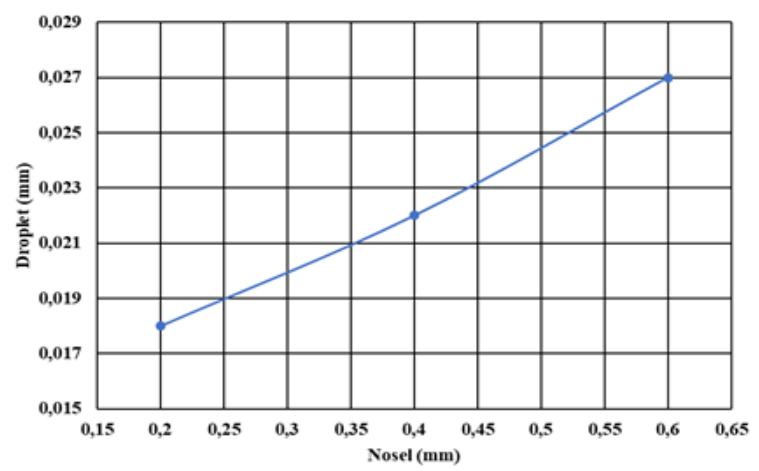

Gambar 2 Grafik hubungan diameter nozzle terhadap diamerter droplet

Grafik 2 menunjukkan diameter B50 minak kelapa dan kapuk pada setiap variasi diameter nozzle pada tekanan 50 bar. Dengan variasi diameter nozzle yang diperbesar droplet yang dihasilkan semakin semakin besar. Hal ini salah satunya dipengaruhi nilai Reinolds number(Afifah, 2019) yang bervariasi berbanding lurus dengan besar diameter nozzle. Karena terjadi perbedaan nilai Reynolds number pada setiap pertambahan diameter nozzle, maka menurut rumus persamaan 
diatas nilai droplet semakin meningkat. Pada pembakaran spray, viskositas bahan bakar berpenaruh terhadap diameter droplet yang dihasilkan. Semakin tinggi nilai viskositas fluida maka kekentalan fluida tersebut semakin tinggi. Hal tersebut mengakibatkan fluida sulit untuk terpecah menjadi droplet. Selain viskositas minyak nabati tegangan permukaan juga berpengaruh terhadap diameter droplet. Karena diameter nozzle yang meningkat pada setiap nozzle yang bervariasi maka secara otomatis tegangan permukaan dari minyak nabati ikut meningkat sehingga diameter droplet yang dihasilkan ikut meningkat lebih besar.

\section{Sudut spray secara teoritis}

Besar sudut spray dapat diperkirakan secara teoritis. Untuk mengetahui besar sudut spray maka dapat menggunakan persamaan sebagai berikut:

$\theta=0,05\left(\frac{\Delta \mathrm{p}_{\mathrm{i}} \mathrm{d}_{\mathrm{o}}^{2}}{\rho_{l} v_{l}^{2}}\right)^{1 / 4}=0.0845$

Karena tekanan terhhadap nozzle sama dan diameter nozzle diperbesar maka secara teoritis sudut spray yang terbentuk mengalami peningkatan.

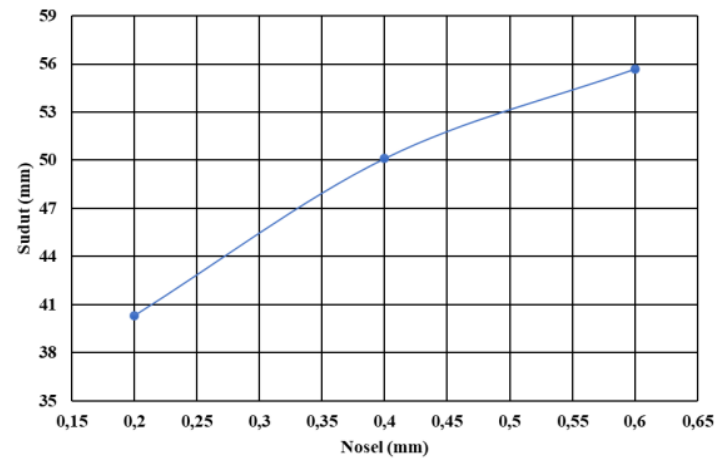

Gambar 4. Grafik hubungan antara diameter lubang nozzle terhadap sudut spray secara teoritis

\section{Sudut spray aktual}

Hasil pengujian sudut spray pada tekanan 50 bar menggunakan minyak B50 kelapa dan kapuk dengan variasi nozzle 0,2, 0,4, 0,6 mm.
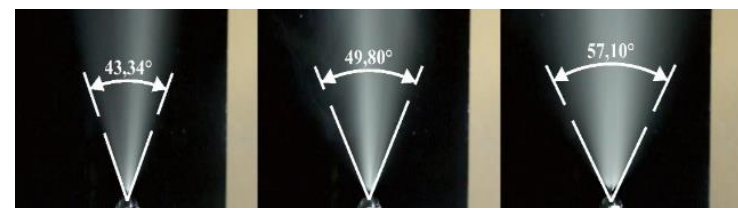

Gambar 3. Hubungan variasi nozzle terhadap sudut spray

Diameter nozzle berperan terhadap sudut spray. Pada gambar 3 dengan tekakanan yang konstan 50 bar dan nozzle yang bervariasi terjadi perubahan sudut yang sangat signifikan. Pada diameter lubang nozzle 0.2 sudut spray yang terbentuk $43,34^{\circ}$, saat diameter lubang nozzle diperbesar menjadi 0,4 terjadi peningkatan penyebaran droplet sebesar 7,520, sudut yang terbentuk pada diameter lubang nozzle 0,4 sebesar $49,8^{\circ}$. Ketika diameter lubang nozzle dinaikan lagi dari $0,4 \mathrm{~mm}$ menjadi $0,6 \mathrm{~mm}$ sudut spray yang terbentuk meninggat menjadi $57,10^{\circ}$, sehingga terjadi peningkatan sudut spray sebesar $12,69^{\circ}$. Perpindahan diameter lubang nozzle dari 0,4 menjadi 0,6 membentuk sudut spray lebih besar $5,17^{\circ}$ jika dibandingkan dengan perpindahan diameter lubang nozzle 0,2 menjadi diameter lubang nozzle 0,4.

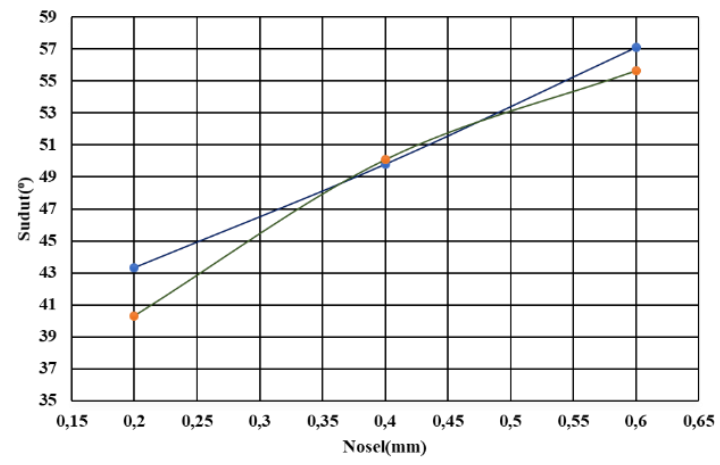

Gambar 5. Grafik hubungan diameter nozzle terhadap sudut spray

Peningkatan diameter lubang nozzle dari 0,2 mm ditingkatkan menjadi $0,4 \mathrm{~mm}$ dan $0,6 \mathrm{~mm}$ terjadi perubahan sudut spray. Sudut spray paling kecil terjadi pada diameter lubang nozzle $0,2 \mathrm{~mm}$ dengan sudut penebaran sebesar 43,34\%, jauh lebihh kecil jika dibandingkan dengan nozzle 0,6 dimana sudut penyebaran sebesar 57,1 ${ }^{\circ}$ jika dibandingkan dengan sudut secara teoritis, sudut spray secara actual pada nozzle diameter 0,2 dan 0,6 memiliki nilai lebih besar tetapi pada diameter nozzle 0,4 memiliki sudut penyebaran yag lebih kecil. Disisi lain minyak kelapa dan minyak kapuk termasuk golongan minyak polar yang memiliki rantai panjang asam lemak dan rentan terhadap oksidasi, hal tersebut mengakibatkan viskositas minyak kelapa dan kapuk tinggi. Viskositas yang tinggi pada minyak kapuk dan kelapa mengakibatkan laju aliran bahan bakar terhambat, tetapi dengan variasi diameter nozzle yang semakin besar hambatan laju aliran minyak nabati pada saat melewati lubang nozzle akan berkurang dan hal tersebut berpengaruh terhadap besar sudut spray yang dihasilkan.

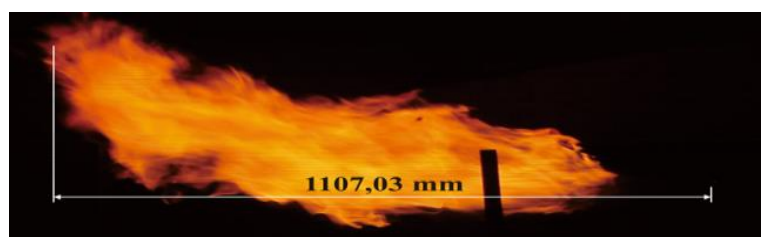

Gambar 6. hubungan diameter nozzle terhadap panjang nyala api 


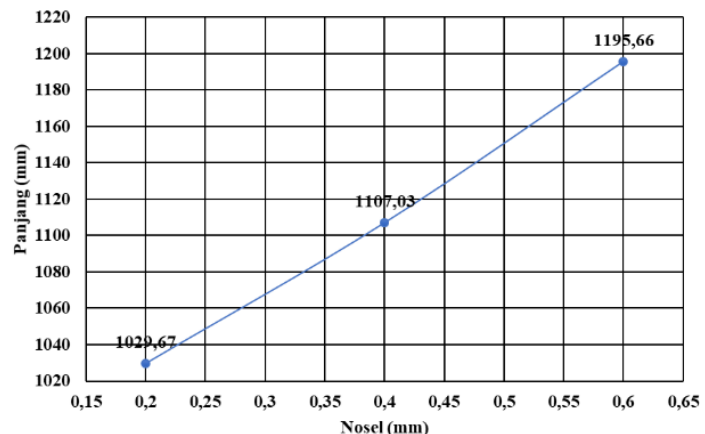

Gambar 7. Grafik hubungan diameter nozzle terhadap panjang nyala api

Terlihat pada grafik tersebut bawha semakin besar diameter nozzle berdampak terhadap nyala api, pertambahan panjang nyala api terjadi salah satunya dipengaruhi oleh debit bahan bakar Dari perhitungan secara teoritis debit bahan bakar paling kecil terdapat pada diameter nozzle $0,2 \mathrm{~mm}$ sedangkan debit paling besar terjadi pada nozzle 0,6 $\mathrm{mm}$. Peningatan debit setiap diameter nozzle secara otomatis juga akan meningkatkan intensitas droplet yang di hasilkan. Jika ditinjau sifat-sifat bahan bakar kedua bahan bakar pada tabel 2.2 minyak kapuk dan minyak kelapa sama sama memiliki flash poin yang tinggi jika dibandingan dengan minyak minyak bumi dan memiliki tingkat penguapan yang sangat rendah (Perdana, Wardana, Yuliati, \& Hamidi, 2018). Tingat penguapan yang rendah pada bahan bakar mengakibatkan proses difusi bahan bakar dengan oksidator terjadi pada daerah yang lebih luas (Sasongko, 2018). Dengan meningkatnya debit bahan bakar dan dimensi droplet yang dihasilkan semakin besar pada variasi diameter nozzle, proses pembakaran terjadi lebih panjang agar droplet terbakar secara keseluruhan. Menurut teori, hal ini berhubungan dengan nilai burning rate, dimana proses pembakaran yang terjadi dengan cepat akan menghasilkan ukuran api yang lebih kecil dibandingkan dengan reaksi pembakaran yang berlangsung lambat (Valente, Pasa, Belchior, \& Sodré, 2012). Selain itu mekanisme bahan bakar cair dapat terbakar sebelumnya akan melewati fase penguapan terlebih dahulu sebelum kemudian berdifusi dengan oksidator membentuk reaktan kemudian terbakar.

\section{Hubungan variasi diameter nozzle terhadap forward dan flashback nyala api pada tekanan 50 bar Forward flame 100mm}

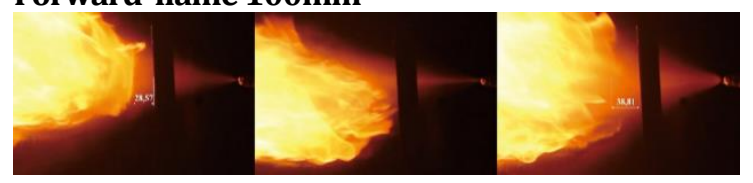

Gambar 8. Forward flame $100 \mathrm{~mm}$ dari ujung nozzle

Gambar 8 menunjukan bahwa terjadi forward flame pada saat pemantik atau sumber nyala api berada pada posisi $100 \mathrm{~mm}$ dari ujung nozzle yang ditandai dengan mistar seperti pada gambar. Pada diameter nozzle 0,2 $\mathrm{mm}$ nyala api terjadi pada 28,57 mm dibelakang penggaris terjadi peningkatan pada saat diameter nozzle diperbesar mnjadi 0,4 mm dimana nyala api diameter nozzle 0,4 mm menempel pada mistar. Sedangkan pada saat diameter nozzle dinaikkan kembali menjadi 0,6 mm ujung nyala api kembali menjauh dari nozzle pada posisi 38,11 mm dibelakang penggaris. Pada tabel 2.2 viskositas minyak kelapa lebih rendah jika dibandingkan dengan minyak kapuk. Karena dalam penelitian ini menggunakan minyak blending kapuk dan kelapa, kemungkinan pada nozzle 0,4 mm minyak kelapa yang paling mendominasi bahan bakar yang di spray sedangkan pada nozzle $0,2 \mathrm{~mm}$ dan 0,6 mm viskositas minyak kapuk mendominasi bahan bakar yang di spray. Karena viskositas kedua bahan bakar berbeda pada minyak yang di blending hal tersebut mengakibatkan poses perubahan bentuk dari sheet, ligament sampai terbentuk menjadi droplets berbeda beda tergantung minyak nabati yang mendominasi.

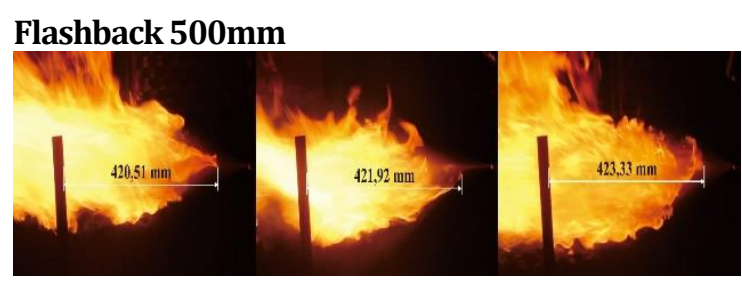

Gambar 9. Flashback nyala api pada posisi pemantik 500 $\mathrm{mm}$

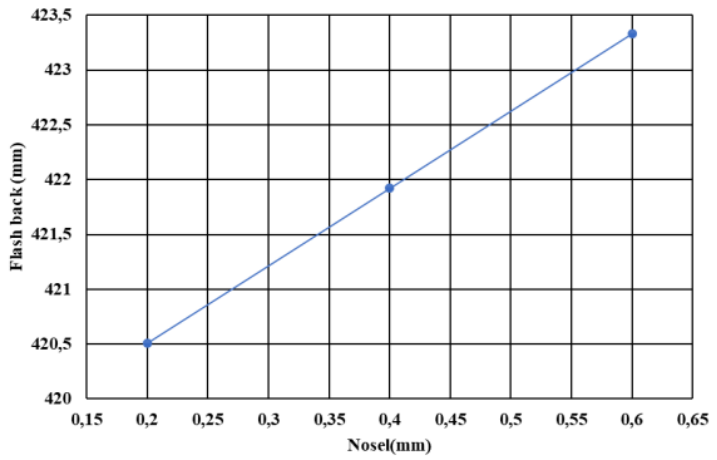

Gambar 10. Grafik hubungan diameter nozzle terhadap Panjang nyala api flashback jarak $500 \mathrm{~mm}$ dari ujung nozzle

Gambar diatas menujukkan terjadi flashback yang cukup panjang pada saat posisi pemantik berada pada posisi $500 \mathrm{~mm}$. pada saat dimeter nozzle 0,2 $\mathrm{mm}$ api flashback sepanjang 420,51 mm terjadi peningkatan terus menerus pada saat diameter nozzle diperbesar. Hal ini menunjukkan bawha pada posisi $500 \mathrm{~mm}$ di depan nozzle bahan bakar sudah berbentuk droplet yang sempurna sehingga dapat terjadi flashback yang cukup panjang. Disisi lain sudut spray berpengaruh terhadap panjang fase terbentuknya drolet yang terjadi. Pada gambar nyala api flashback diatas menujukkan semakin besar sudut spray maka 
panjang api flashback akan semakin panjang tetapi kecepatan pembakaranya menurun karena droplet yang semakin besar.

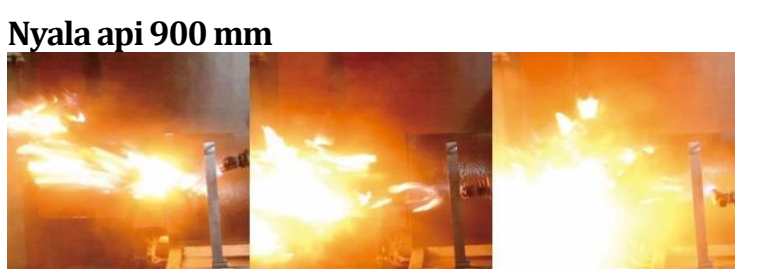

Gambar 11. Nyala api pada posisi pemantik $900 \mathrm{~mm}$ dari ujung nozzle

Gambar 4.10 menunjukkan bahwa pada saat pemantik berada pada posisi $900 \mathrm{~mm}$ dari ujung nozzle, bahan bakar tidak dapat terbakar secara stabil. Pada saat diameter nozzle $0,2 \mathrm{~mm}$ hanya terjadi ledakan kecil bahan bakar pada saat lidah api pemantik menyentuh droplet yang tersebar. Nyala api membesar seiring bertambahnya diameter lubang nozzle. Hal ini disebabkan salah satunya karena debit bahan bakar meningkat pada saat diameter lubang nozzle diperbesar. Sehingga intensitas droplet pada nozzle $0.6 \mathrm{~mm}$ lebih besar dibandingkan dengan diameter nozzle yang kecil. Selain faktor debit bahan bakar kecepatan injeksi bahan bakar juga sudah mulai menurun pada saat droplet mencapai jarak $900 \mathrm{~mm}$ sehingga droplet bahan bakar sudah mulai menyatu kembali membentuk droplet yang lebih besar. Karena pada saat nozzle 0,2 intensitas droplet lebih sedikit dan diameter droplet semakin besar, untuk mencapai temperatur dimana minyak nabati dapat menyala dengan stabil. Sedangkan ledakan droplet terjadi karena dipengaruhi oleh kandungan myristic didalam minyak nabati. Ledakan tersebut merupakan reaksi berantai dari droplet hasil spray. Karena pada nozzle 0,6 mm diameter droplet lebih besar maka secara otomatis tegangan permukaan droplet tersebut ikut besar, pada saat tegangan perukaan droplet besar reaksi berantai pada drolet tersebut lebih panjang.

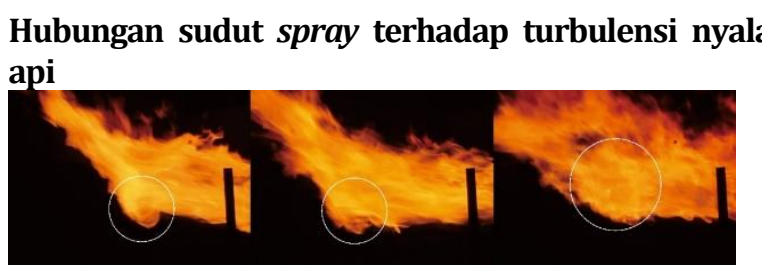

Gambar 12. Turbulensi nyala api

Gambar 4.11 menunjukkan perbedaan turbulensi terjadi pada setiap diameter nozzle, turbulensi nyala api paling besar terjadi pada diameter nozzle 0,6 sedangkan turbulensi paling lecil terjadi pada diametr nozzle 0,2. Fenomena ini terjadi karena dipengaruhi oleh sudut spray yang berbeda pada setiap diameter nozzle, dimana nozzle paling besar memiliki sudut spray paling besar dan turbulensi yang terjadi juga semakin besar.

\section{PENUTUP}

\section{Kesimpulan}

Dari penelitian yang dilakukan selama ini, didapat beberapa kesimpulan yang tertera dibawah ini :

1. Diameter droplet yang dihasilkan berbanding lurus dengan semakin besarnya diameter nozzle, sebaliknya diameter droplet yang derbanding lurus dengan diameter nozzle yang semakin kecil.

2. Bertambahnya panjang nyala api dipengaruhi oleh meningkatnya diameter nozzle

3. Semakin meningkatnya sudut spray seiring dengan semakin besarnya diameter nozzle,

4. Dengan variasi penyalaan awal, flashback hanya terjadi pada jarak penyalaan awal $500 \mathrm{~mm}$, sedangkan pada jarak penyalaan awal $100 \mathrm{~mm}$ dan $900 \mathrm{~mm}$ hanya terjadi forward flame dan ledakan nyala api

5. Terjadi perbedaan turbulensi nyala api pada variasi nozzle, dimana semakin besar diameter nozzle maka semakin besar turbulensi nyala api yang terjadi.

\section{DAFTAR PUSTAKA}

Afifah, Y. N. (2016). ALIRAN TAK TUNAK FLUIDA NANO MAGNETOHIDRODINAMIK ( MHD) YANG MELEWATI BOLA.

Afifah, Y. N. (2019). Analysis of Unsteady Magneto Hydro Dynamic (MHD) Nano Fluid Flow Past A Sliced Sphere. IOP Conference Series: Materials Science and Engineering, 494(1). https://doi.org/10.1088/1757899X/494/1/012033

Afifah, Y. N., \& Putra, B. C. (2018). Model Matematika Aliran Tak Tunak Pada Nano Fluid Melewati Bola Teriris Dengan Pengaruh Medan Magnet. Teknika: Engineering and Sains Journal, 2(2), 119-124.

Denitasari, N. A. (2011). Briket Ampas Sagu Sebagai Bahan Bakar Alternatif.

Gunawan, E. et al. (2019) 'Analysis of the Effect of Current Flow Variations in GTAW on SS 400 Plate Material Connected with SUS 304 Stainless Steel Plate Against Tensile Strength and Hardness with ER308L Electrodes', Journal of Physics: Conference Series, 1175(1). doi: 10.1088/1742-6596/1175/1/012277.

Juniarta, I. K., Wirawan, I. K. G., \& Ghurri, A. (2017). Studi Eksperimental Pengaruh Variasi Tekanan Terhadap Sudut Semburan Minyak Jelantah. 6(2), 2-6.

Perdana, D., Wardana, I. N. G., Yuliati, L., \& Hamidi, N. (2018). The role of fatty acid structure in various pure vegetable oils on flame 
characteristics and stability behavior for industrial furnace. Eastern-European Journal of Enterprise Technologies. https://doi.org/10.15587/17294061.2018.144243

Pinto, A. (2015). UJI KARAKTERISTIK PENYEMPROTAN BAHAN BAKAR BIODIESEL PADA Characteristics Test Of Biodiesel Fuel Spraying On Nozzle Diesel Engine With Direct Injection System. 15(1), 1-5.

Putra, B. C., \& Afifah, Y. N. (2018). Gaussian Mixture Model Untuk Penghitungan Tingkat. Teknika: Engineering and Sains Journal, 2, 53-58.

Sasongko, M. N. (2018). Pengaruh Prosentase Minyak Goreng Bekas Terhadap Karakteristik Pembakaran Droplet Biodiesel. IV(2).

Subbarao, P. M. V. (n.d.). Design of Port Injection Systems for SI Engines.

Sudarmanta, B. (2017). STUDI EKSPERIMENTAL PENGARUH TEMPERATUR PEMANASAN BAHAN BAKAR BIODIESELPALM OIL (B100) TERHADAP UNJUK KERJA MESIN DIESEL SISTEM INJEKSI LANGSUNG DIAMOND TIPE Di800. (April).

Udin, M., Yuliati, L., \& Novareza, O. (2017). Pengaruh Persentase Biodiesel Minyak Nyamplung Solar terhadap Karakteristik Pembakaran Droplet. Jurnal Rekayasa Mesin, 8(1), 9-14. https://doi.org/10.21776/ub.jrm.2017.008.0 1.2

Valente, O. S., Pasa, V. M. D., Belchior, C. R. P., \& Sodré, J. R. (2012). Exhaust emissions from a diesel power generator fuelled by waste cooking oil biodiesel. Science of the Total Environment.

https://doi.org/10.1016/j.scitotenv.2012.05. 025

Wibawa, I. W. S., Bagus, I. G., Kusuma, W., \& Nyoman, I. (2015). Uji Variasi Tekanan Nosel Terhadap Karakteristik Semprotan Bahan Bakar Biodiesel. 1(2), 35-44.

Wirawan, I. K. G., Wardana, I. N. G., Soenoko, R., \& Wahyudi, S. (2014). Combustion of Jatropha Curcas oil on perforated burner. Energy Education Science and Technology Part A: Energy Science and Research.

Yunita Nur Afifah, MNH Qomarudin and Imamatul Ummah (2020) 'Optimal Control Model Pemanenan Prey-Predator di Area Konservasi Ikan', Buana Matematika: Jurnal Ilmiah Matematika dan Pendidikan Matematika, 10(1), pp. 1-16. doi: 10.36456/buanamatematika.v10i1.2410. 